\title{
Water intake, spontaneous learning for food, activity, and manipulation for talapoin and squirrel monkeys'
}

C. E. THOMSEN and T. H. CLIEWL, Divisions of Behavioral Science and (jentic and Developmental Disorders. Tulane University Delta Regional Primate Research Center, Covington, La. 70433

Talapoin and squirrel monkeys were compared on measures of water consumption, general activity, manipulation of objects, and acquisition of a spontaneous learning task. The talapoin consumed a large amount of water per kilogram of body weight compared to the squirrel monkey. The talapoin also was very active and manipulated objects whereas the squirrel monkey was inactive and did not manipulate objects. Furthermore, the tulapoin demonstrated a marked superiority on a spontaneous learning task. It is suggested that the talapoin is an excellent alternative to Saimiri in most behavioral tasks requiring a high level of responsiveness.

The squirrel monkey (Saimiri sciureus), a New World monkey (NWM), has been widely used during the last decade in behavioral and biomedical research because of its size, availability, and adaptability in the laboratory. Its importance is illustrated in the following statement by Rosenblum \& Cooper (1968) that, "Among the primates which recently have become major foci of research interest, none has exceeded the common South American squirrel monkey, Saimiri sciureus, in terms of widespread acceptance and use. Their status near the middle of the primate evolutionary scale makes relatively complex behavioral tasks well within their repertoire and places their physiological functioning on a level at which significant comparative work may be carried out."

The talapoin /Ceropithecus (miopithecus) talapoin), an Old World monkey (OWM), is only slightly larger than the squirrel monkey. All other truly small primates are either prosimians or NWM, and thus the talapoin is man's nearest diminu tive relative. Despite its size, Schrier \& Povar (1968) have found that the talapoin performs very well in WGTA adaptation procedures, readily learned a color and form discrimination learning-set task, and may even adapt as well as or more readily than rhesus monkeys. Furthermore, Cooper \& King (1968) suggest that it is not a difficult species to maintain in captivity and anticipate that it will become increasingly available for research. Because the performance of OWM on behavior tests is generally superior to that of NWM (Polidora, 1964) and because of similarities of the brain and other anatomical features of the talapoin to other Cercopitheques (Hill, 1966), the talapoin may provide a more suitable model for the investigation of human bio-behavior problems than the squirrel monkey and yet retain most of the practical advantages of a small primate.

The present study provides comparative data for female talapoin and squirrel monkeys on several behavioral tests designed to assess general responsiveness. These tests include measures of water consumption, general activity, manipulation, and acquisition of a spontaneous learning task. They are part of a larger battery being developed at the Delta Primate Center to provide a broad spectrum assessment of motivational-emotional behaviors of primates under a variety of environmental conditions. These measures, rather than more complex learning tasks, have been used in initial testing of talapoin and squirrel monkeys for the following reasons: (1) interpretation of differences between species on complex learning tasks is dependent on use of optimum motivational conditions (Bitterman, 1965), and thus motivational analyses are a necessary first step toward analysis of learning data; and (2) there is some evidence that the "intellectual" capacity of subhuman primates correlates with their general responsiveness (Morris, 1964; Glickman \& Sroges, 1966).

\section{SUBJECTS}

Four adult female, wild-caught talapoins and four adult female, wild-caught squirrel monkeys (mean weight 1,052 and $630 \mathrm{~g}$, respectively) were used. The talapoins had no previous behavioral testing and had been maintained in pairs for approximately 3 months after their arrival at the laboratory. The squirrel monkeys had been maintained in a larger group at the center for approximately 1 year and were used in social experiments, but had not been used in experiments similar to the present investigation.

\section{APPARATUS}

The Ss were tested in individual cages, each $2 \times 2.5 \times 3 \mathrm{ft}$ and constructed of sheet aluminum. The front of each cage consisted of a clear plastic door above a second door of sheet metal (each $14 \times 14$ in.). These doors were replaced with an expanded metal door after 5 days of testing, but no obvious behavioral effects occurred. The floor of each cage was constructed of 5/8-in. stainless steel bars placed $7 / 8$ in. apart.

The following test equipment was mounted on each cage: (1) A light source and a photocell bisected the cage. The output of the photocell was connected to an electromagnetic counter. (2) Two manipulation springs (one moveable and one nonmoveable) were placed in a vertical position 1.25 in. from the outside of the cage in a $8 \times 5 \times 2.5 \mathrm{in}$. box, which was accessible through two 2.5-in. circular openings. Both springs were connected to a contact sensor and its output connected to a counter. (3) A fluid intake device patterned after that used by Povar \& Salk (1965) was mounted $12 \mathrm{in}$. above the floor and placed on one side of the test cage, 6 in. from the front of the cage. An inverted " $L$ " tube required that the animal learn to suck to obtain water. (4) An operandum, consisting of a $1.25 \times 1.25 \mathrm{in}$. piece of electrically conductive glass, required only a touch to actuate a solid-state programmer which operated a food dispenser.

In addition to the above test equipment, white noise was used to mask extraneous sounds. A 15-W light bulb above each cage and a fluorescent light in the center of the room were turned on at 6 a.m. and turned off at 6 p.m.

\section{PROCEDURE}

All Ss were tested at the same times on the following schedule: Water consumption ( $24 \mathrm{~h}$ per day) and general activity (between 8 a.m. and 4 p.m.) were recorded for 19 days. A 3-week period in expanded metal cages $(2 \times 2 \times 3.5 \mathrm{ft})$ was then given to obtain some indication of food preferences preparatory to fixed-ratio training. Animals were returned to the original test cages to obtain manipulation scores during six 2 -h recording sessions $(9$ to $11 \mathrm{a} . \mathrm{m}$. and 2 to 4 p.m. on each of 3 days) and to obtain acquisition rates of a glass-touch response on

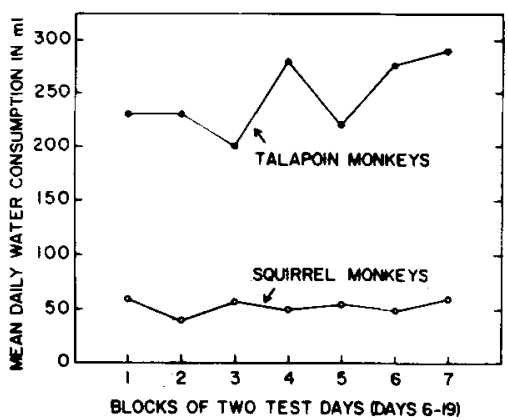

Fig. 1. Mean daily water consumption in milliliters for talapoin and squirrel monkeys for blocks of $\mathbf{2}$ test days. 


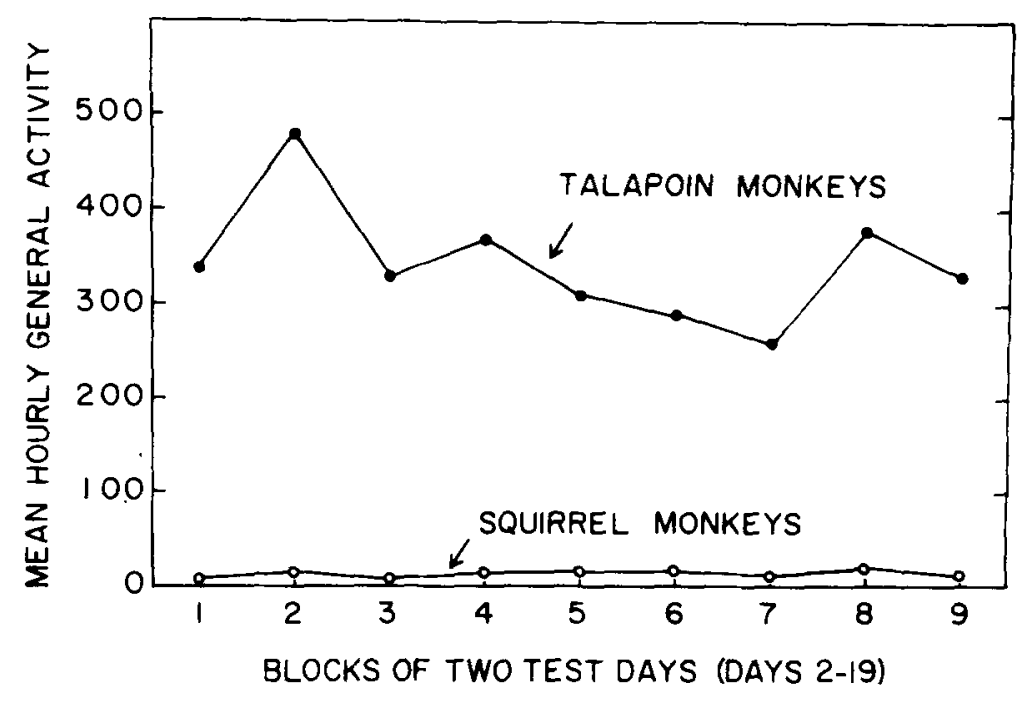

a stepping fixed-ratio (FR) schedule. The schedule started at FR 1 and the ratio was doubled in each session following the one in which the animal received at least 50 pieces of fruit. No E shaping of the response was performed. A blinking red light behind the operandum signaled the onset of the $30-\mathrm{min}$ session. The $30-\mathrm{min}$ session occurred during one of the four $30-\mathrm{min}$ periods of the $2-\mathrm{h}$ session. Manipulations were recorded throughout the session. All animals were fed their regular diet of Purina chow at $8 \mathrm{a} . \mathrm{m}$. and 4 p.m.

\section{REESULTS}

Because Ss had to learn to suck to obtain water, the mean' daily water consumption was obtained by averaging only the last 14 days of testing when all Ss were sucking efficiently. Mean daily water consumption during this period was $254 \mathrm{ml}$ for the talapoins and $52 \mathrm{ml}$ for the squirrel monkeys $(240 \mathrm{ml}$ and $80 \mathrm{ml}$, respectively, per kilogram of body weight; $\mathrm{t}=3.20$; $\mathrm{df}=3 ; \mathrm{p}<.05)$. Degrees of freedom for the test were halved (Winer, 1962) because of the large differences in variability for the talapoins (estimated $\sigma=.098$ ) compared to the squirrel monkeys (estimated $\sigma=.017$ ) $(\mathrm{F}=32.33 ; \mathrm{df}=3,3 ; \mathrm{p}<.02)$. Mean daily water consumption averaged in 2 -day blocks

Table 1

Number of Responses (R) and Fixed Ratio Schedule (FR) by Session for Individual Talapoins

\begin{tabular}{|c|c|c|c|c|c|c|c|}
\hline \multirow{2}{*}{$\begin{array}{l}\text { Animal } \\
\text { Number }\end{array}$} & & \multicolumn{6}{|c|}{ Session } \\
\hline & & 1 & 2 & 3 & 4 & 5 & 6 \\
\hline 41 & $\begin{array}{l}\mathrm{R} \\
\mathrm{FR}\end{array}$ & $\begin{array}{l}0 \\
1\end{array}$ & $\begin{array}{l}0 \\
1\end{array}$ & $\begin{array}{l}0 \\
1\end{array}$ & $\begin{array}{l}0 \\
1\end{array}$ & $\begin{array}{l}0 \\
1\end{array}$ & $\begin{array}{l}0 \\
1\end{array}$ \\
\hline 43 & $\begin{array}{l}\text { R } \\
\text { FR }\end{array}$ & $\begin{array}{l}1 \\
1\end{array}$ & $\begin{array}{r}24 \\
1\end{array}$ & $\begin{array}{r}126 \\
1\end{array}$ & $\begin{array}{r}214 \\
2\end{array}$ & $\begin{array}{r}176 \\
2\end{array}$ & $\begin{array}{r}114 \\
4\end{array}$ \\
\hline 44 & $\begin{array}{l}\mathbf{R} \\
\mathrm{FR}\end{array}$ & $\begin{array}{r}50 \\
1\end{array}$ & $\begin{array}{r}196 \\
2\end{array}$ & $\begin{array}{r}273 \\
4\end{array}$ & $\begin{array}{r}280 \\
8\end{array}$ & $\begin{array}{r}258 \\
8\end{array}$ & $\begin{array}{r}276 \\
8\end{array}$ \\
\hline 46 & $\begin{array}{l}\mathrm{R} \\
\mathrm{FR}\end{array}$ & $\begin{array}{l}0 \\
1 \\
\end{array}$ & $\begin{array}{l}3 \\
1 \\
\end{array}$ & $\begin{array}{l}9 \\
1 \\
\end{array}$ & $\begin{array}{r}105 \\
1 \\
\end{array}$ & $\begin{array}{r}502 \\
2 \\
\end{array}$ & $\begin{array}{r}499 \\
4 \\
\end{array}$ \\
\hline
\end{tabular}

Fig. 2. Mean hourly general activity for talapoin and squirrel monkeys for blocks of 2 test days.

first day was not used in Fig. 2 because of missing data for one animal). Only a small decrease in activity for the talapoins occurs over this test period, whereas the squirrel monkeys maintained a low, but relatively stable, amount of activity.

The total number of contacts with the springs for the talapoins for the six 2-h recording sessions combined is 313 (one talapoin did not make contact). Only one squirrel monkey made contact with the devices during any of the six test sessions. The number of contacts for each of the six 2-h recording sessions is graphed in Fig. 3. Inspection of the graphs indicates a large number of contacts in the first three sessions for the talapoins with few responses thereafter.

for the last 14 days is given in Fig. 1 and indicates that there may be a small increase in consumption for the talapoins and no increase for the squirrel monkeys.

The values for water consumption undoubtedly underestimate the requirement for fluids since the food given during this period consisted in part of Purina lab chow soaked for approximately $2 \mathrm{~min}$ in water. It is estimated that the talapoin and squirrel monkeys received approximately 5 to $10 \mathrm{ml}$ of water daily from the soaked food. This was not added to the daily totals. In addition to the monkey chow, both talapoin and squirrel monkeys typically ate 15 to 25 very small pieces of fruit daily ( 25 pieces were offered daily). Although water content was not estimated, the fruit also helped to meet requirements for fluids.

Mean hourly activity scores (photo-cell interruptions, based on 19 days of recording) were 323.6 and 12.9 for the talapoin and the squirrel monkeys, respectively $(t=5.24 ; d f=3 ; p<.02)$. Estimated standard deviations of 118.03 and 12.00 were obtained for the talapoin and squirrel monkeys, respectively $(F=96.79 ; \quad d f=3,3 ; \quad p<.02) . \quad$ Figure 2 plots the mean hourly activity for talapoin and squirrel monkeys for 2-day blocks (the

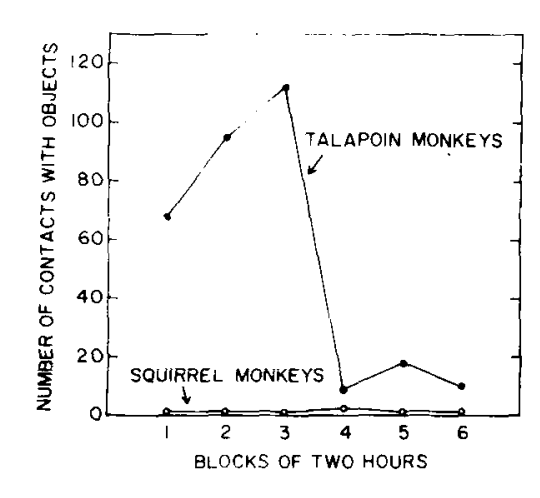

Fig. 3. Number of contacts with objects for talapoin and squirrel monkeys for blocks of $2 \mathrm{~h}$.

In acquisition of the glass-touch response, three out of four talapoins learned the task, whereas none of the squirrel monkeys made a single response to the glass. The number of responses for each of the talapoins during each of the 30 -min sessions and the fixed-ratio schedule reached in each session is given in Table 1. Animal 44 pressed during the first session and maintained responding during successive increases to FR 8 in the fourth session. Two other animals were on FR 4 by the sixth session, and overall, the talapoins averaged 222 presses during this session.

Because squirrel monkeys are deficient in the red end of the spectrum, they were run an additional 5 days with two other colored lights (yellow and green). The new lights did not appear to make any difference. Although one animal made 11 responses on Day 1 with the new lights and 7 responses on Day 2, it did not respond on Days 3-5. No other squirrel monkey made any responses during the additional five sessions. 


\section{DISCUSSION}

The data indicate that the talapoin consumes a large quantity of water per kilogram of body weight compared to the squirrel monkey. The talapoins are also very active, manipulate objects frequently, and rapidly improve on a spontaneous learning task. The squirrel monkey is very inactive, does not manipulate objects, and did not learn the spontaneous learning task. These data suggest that the talapoin adapts readily to an experimental regimen, is responsive to the experimental environment and readily learns simple instrumental responses. It would appear to be an excellent alternative to Saimiri, particularly for tasks requiring a high level of behavioral responsiveness.

It is also of interest to compare the data on talapoins and squirrel monkeys to other data on the stumptail (Macaca speciosa) and rhesus (Macaca mulatta) monkeys obtained at the Delta Center. ${ }^{2}$ The talapoin consumes $240 \mathrm{ml}$ water $/ \mathrm{kg}$ body weight, while the stumptail consumes approximately $180 \mathrm{ml} / \mathrm{kg}$. The squirrel monkey consumes approximately the same amount of water as the rhesus (approximately $80 \mathrm{ml} / \mathrm{kg}$ ). Although the experiments involved in the unpublished data differed somewhat in method from the present one, both the talapoins and stumptails had high rates of manipulation of objects and both rapidly increased to higher ratios on the spontaneous learning task. Furthermore, the talapoins are at least as high in manipulation and as proficient in the spontaneous learning task as the rhesus monkeys. These limited data available on different species of animals tentatively suggest that there may be high intraspecies correlations between seemingly diverse measures of general responsiveness.

\section{REFERENCES}

BITTERMAN, M. E. Phyletic differences in learning. American Psychologist, 1965, 20, 396-410.

COOPER, R. W., \& KING, A. A. Availability and biomedical research utility of the talapoin monkey, Cercopithecus (Miopithecus) talapoin. Laboratory Primate Newsletter, 1968, 7, 48.

GLICKMAN, S. E., \& SROGES, R. W. Curiosity in zoo animals. Behaviour, 1966, 26, 151-188.

MORRIS, D. The response of animals to a restricted environment. Symposium of the Zoological Society of London, 1964, 13, 99-118.

POLIDORA, V. J. Learning abilities of new world monkeys. American Journal of Physical Anthropology, 1964, 22, 245-252.

POVAR, M. L., \& SALK, R. A device for measuring fluid in take by primates. Journal of the Experimental Analysis of Behavior, 1965, 8, 187-188.

ROSENBLUM, L. A., \& COOPER, R. W. (Eds.), The squirrel monkey. New York: Academic Press, 1968.

SCHRIER, A. M., \& POVAR, M. L. A note on the talapoin monkey, Cercopithecus (Miopithecus) talapoin, as a laboratory animal. Laboratory Primate Newsletter, 1968, 7, 9-11.

WINER, B. J. Statistical principles in experimental design New York: McGraw-Hill, 1962. NOTES

1. This work was supported in part by NIH Grant FR-00164 and by NIH Grant FR-00398-01 to Dr. T. H. Clewe.

2. C. E. Thomsen, Unpublished data.
The present study was undertaken to determine the effect of the visual contribution to the enriched-environment effect. To test the effect, two strains of rats were used: albino, which has a poor visual system, and hooded, which has a comparatively good visual system. The amount of light experience given the rats was varied to separate further the visual experience the animals received. Two testing sessions were given, one in the light followed by one in the dark, using the Hebb-Williams maze (Rabinovitch \& Rosvold, 1951).

METHOD AND PROCEDURE

The Ss were 60 male and female rats (28 albino, 32 hooded) from the colony at the University of Vermont. A 2 by 2 by 2 factorial design, with the following variables, was used: (a) Free and restricted environment conditions-The free environments consisted of two $4 \mathrm{ft} \times 4 \mathrm{ft} \mathrm{x}$ $8 \mathrm{in}$. wire mesh cages, elevated $4 \mathrm{ft}$ from the floor. The restricted environments were 16 $9 \times 15$ in. laboratory cages (Forgays \& Forgays, 1952). (b) Light and limited-light conditions-The light condition was a $7 \times 9 \mathrm{ft}$ room, illuminated $24 \mathrm{~h}$ a day; the limited-light condition was a similar room kept completely dark $23 \mathrm{~h}$ a day. Both rooms contained one free-environment cage and eight restricted-environment cages. (c) The third variable was animal strain-albino and hooded.

At 21 days of age, the rat pups were weaned and assigned, by the split-litter technique, to the various rearing conditions. The cages in the light and limited-light conditions were rotated over several positions once every week to counteract any positional effects. All Ss were on an ad lib food and water diet throughout rearing. Each animal was handled for $1 \mathrm{~min}$ each week in an attempt to acclimate him to handling and to reduce possible emotionality differences associated with differential isolation.

At 90 days of age, all animals were marked and put into $9 \times 15$ in. laboratory cages. Two days later, each animal was given two 5-min trials in a Hall-type (Hall, 1934) emotionality pen. Activity within the pen provided three separate scores: (1) total area covered, (2) distance penetration from the walls to the center of the $8-\mathrm{ft}$ circular pen, and (3) a composite score made up of the first two by assigning weights to the various concentric circles and sectors of the pen. Defecations were also counted. On the day following the emotionality testing, the Ss were put on a 23-h food-deprivation schedule. On the following day, they began adaptation to the Hebb-Williams maze in the light.

One week following the completion of the light testing, the Ss were readapted to 